\title{
PERBANDINGAN KEMAMPUAN FISIK PETINJU NASIONAL DENGAN PETINJU DAERAH DI KALIMANTAN SELATAN
}

Hegen Dadang Prayoga

\author{
(Universitas Islam Kalimantan Muhammad Arsyad Al Banjari ) \\ hegen.dadang.prayoga@gmail.com
}

\begin{abstract}
ABSTRAK
Proses pelaksanaan penelitian ini, dimulai dari pengajuan proposal, seminar, pengurusan perizinan, pengambilan data kemampuan fisik sampai pada perhitungan statistik menggunakan kalkulator dan komputer dalam menganalisis data. Setelah dilaksanakan pengambilan data tingkat kemampuan fisik petinju melalui instrumen Tes Kemampuan fisik petinju dapat diperoleh data tingkat kemampuan fisik petinju Nasional dan tingkat kemampuan fisik Daerah. Selanjutnya dilakukan uji persyaratan analisis dengan menggunakan uji runtun, uji normalitas dan uji homogenitas. Setelah pengujian persyaratan dipenuhi, maka dilaksanakan pengujian hipotesis penelitian dengan melakukan uji dua rata-rata atau uji dua pihak dengan membandingkan nilai t yang diperoleh dari perhitungan dengan nilai t pada tabel. Hasil yang diperoleh adalah $\quad-1,76<1,34<1,76$ atau $\mathrm{t}$ hitung $=$ 1,34 terletak antara -1,76 dan 1,76 pada tarap nyata 0,05 sehingga dapat disimpulkan tidak terdapat perbedaan antara tingkat kemampuan fisik petinju Nasional dengan petinju Daerah Kalimantan Selatan.
\end{abstract}

Kata Kunci: kemampuan fisik.

\begin{abstract}
The process of carrying out this research, starting from the submission of proposals, seminars, management of licensing, physical capability data retrieval to statistical calculations using calculators and computers in analyzing data. After data retrieval is carried out on the level of physical abilities of boxers through the Test instrument boxers' physical abilities can be obtained data on the level of physical ability of the National boxer and the level of physical ability of the area. Then the analysis requirements test was carried out by using the test series, normality test and homogeneity test. After the testing requirements are met, the research hypothesis testing is carried out by conducting a two-test average or two-party test by comparing the t value obtained from the calculation with the value of $t$ in the table. The results obtained are $-1.76<1.34<1.76$ or $t$ count $=1.34$ located between -1.76 and 1.76 on the real level of 0.05 so that it can be concluded that there is no difference between the level of physical ability of the boxer National with the South Kalimantan Regional boxer
\end{abstract}

Keywords:physical ability.

Dipublikasikan Oleh :

UPT Publikasi dan Pengelolaan Jurnal

Universitas Islam Kalimantan Muhammad Arsyad Al-Banjari Banjarmasin 


\section{PENDAHULUAN}

Kejuaraan Tinju amatir yang sering digelar merupakan salah satu tolak ukur untuk mengetahui sejauh mana pembinaan cabang olahraga tinju amatir di masing - masing daerah. Akhir - akhir ini prestasi tim tinju amatir Kalimantan Selatan belum pernah menjadi juara umum dalam mengikuti kejuaraan nasional. Minimnya prestasi yang diperoleh tim tinju Kalimantan Selatan ditingkat nasional, sudah tentu akan menjadi pemikiran bagi para Pembina, pelatih, orang tua atlet dan semua yang terlibat didalamnya. Salah satu faktor yang perlu diketahui dengan segera adalah tingkat kemampuan fisik atlet karena kemampuan fisik seorang atlet dapat dikatakan sebagai keadaan yang memberikan ciri tentang derajat atau tingkat kemampuan seseorang di dalam melakukan kegiatan, baik itu kegiatan dalam bertanding maupun dalam berlatih. Oleh karena itu baik petinju daerah maupun petinju nasional harus mempunyai kemampuan fisik yang baik karena latihan akan terus terjadi peningkatan untuk kedepan bukan terjadi penurunan bagi setiap petinju "oleh karena itu kata kunci untuk mencapai prestasi dan keunggulan dalam olahraga adalah berlatih dan prestasi" (Rusli Lutan, dalam Harsuki,2003:364)

Berkaitan dengan hal tersebut diatas, sebagai atlet tinju amatir Kalimantan Selatan perlu kiranya untuk mengetahui apakah ada perbandingan kemampuan fisik antara petinju daerah dengan petinju nasional di Kalimantan Selatan. Karena para ahli sepakat bahwa "hanya atlet yang memiliki kemampuan fisik prima yang mampu berlatih secara optimal. Dan hanya atlet yang berlatih secara optimal yang memungkinkan perolehan prestasi optimal pula“. (Moch Moeslim,dalam Harsuki,2003:318)

Permasalahan dominan dalam penelitian ini adalah ada atau tidaknya perbandingan kemampuan fisik antara petinju daerah dengan petinju amatir yang berada di Kalimantan Selatan. Petinju daerah yang belum pernah berada di level nasional apakah mampu bersaing dengan para petinju yang pernah ataupun sering bermain di level nasional. Apabila para petinju daerah tersebut mampu bersaing dengan petinju nasional salah satunya adalah kemampuan fisiknya maka persaingan antara petinju daerah dengan petinju nasional akan semakin ketat sehingga akan semakin banyak generasi yang dimiliki Pengprov PERTINA Kalimantan Selatan. Demikian pula dengan diketahuinya tingkat kemampuan fisik petinju amatir maka kualitas petinju akan dapat ditingkatkan, mengingat kemampuan fisik petinju merupakan salah satu pondasi utama yang harus dimiliki setiap petinju dalam melakukan latihan untuk dapat meraih prestasi puncak, karena tujuan kedepan setiap petinju adalah ingin menggapai prestasi setinggi mungkin bukan hanya di level daerah melainkan di level nasional maupun internasional.

\section{METODE}

Desain penelitian ini berkenaan dengan sebuah metode yaitu suatu cara yang berkenaan dengan bagaimana data dan informasi yang diperlukan dalam penelitian tersebut dapat diperoleh. Jenis penelitian ini adalah penelitian deskriptif kuantitatif yaitu suatu penelitian yang bertujuan mendapat gambaran atau kenyataan yang sesungguhnya dari keadaan objek penelitian dengan didukung dengan data-data berupa angka yang diperoleh dari hasil pengambilan data yaitu tes dan pengukuran. Metode yang digunakan dalam penelitian ini adalah metode survei karena hanya menggambarkan objek yang terbatas. Objek dalam penelitian ini adalah kemampuan fisik dasar cabang olahraga tinju dan subjek adalah para atlet tinju kalimantan selatan yang berlevel di tingkat nasional dan lokal. Instrumen yang digunakan untuk mengumpulkan fakta adalah : Untuk mengukur kemampuan fisik menggunakan Rangkaian Tes Kemampuan Fisik Cabang Olahraga Tinju. (Moch moeslim dalam Harsuki,Perkembangan Olahraga Terkini (2003:329). Sampel penelitian adalah Petinju nasional dan petinju daerah berjumlah 16 orang. Teknik pengambilan sampel dilakukan dengan Purposive Sampling " Pertimbangan peneliti dalam pengambilan sampel yaitu jumlah Petinju yang masih berperan aktif di Pengcab - pengcab dengan kriteria sampel adalah sehat.

\section{HASIL DAN PEMBAHASAN}

Data nilai yang diperoleh dari hasil Tes Kemampuan Fisik Petinju Nasional dan Petinju Daerah Kalimantan Selatan didiskripsikan pada tabel data dibawah ini :

Tabel 1. Nama dan Skor Tes Kemampuan Fisik Petinju Nasional dan Petinju Daerah Kalimantan Selatan serta klasifikasi tingkat kemampuan Fisik Petinju Nasional dan Petinju Daerah Kalimantan Selatan.

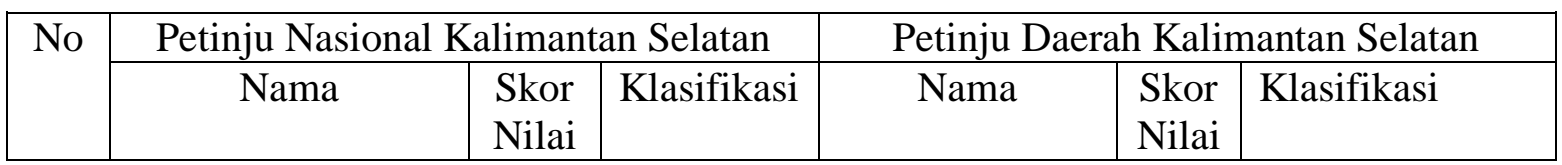

Dipublikasikan Oleh :

UPT Publikasi dan Pengelolaan Jurnal

Universitas Islam Kalimantan Muhammad Arsyad Al-Banjari Banjarmasin 


\begin{tabular}{|l|l|c|c|l|c|c|}
\hline 1 & Asad Adha & 3.4 & Sedang + & Arbain & 2.8 & Sedang - \\
\hline 2 & Bambang. P & 3.4 & Sedang + & Elener .B.. S & 4.2 & Baik \\
\hline 3 & Firmasyah & 2.9 & Sedang - & Fadli Risman & 3.1 & Sedang \\
\hline 4 & Hendra . K & 3.8 & Baik - & Fauzi .R & 3.0 & Sedang \\
\hline 5 & Hendra. P & 3.4 & Sedang + & Hery .P & 3.1 & Sedang \\
\hline 6 & Johan . R & 3.4 & Sedang + & M. Syarif. H & 2.2 & Kurang \\
\hline 7 & M. Idris & 3.6 & Sedang + & M. Zailani & 3.5 & Sedang + \\
\hline 8 & Tri Putra & 3.4 & Sedang + & Prasetyo & 2.9 & Sedang - \\
\hline & Jumlah & 27.3 & Sedang + & Jumlah & 24.8 & Sedang - \\
& Rata-rata & 3.4 & & Rata-rata & 3.1 & \\
& Standar deviasi & 0.25 & & Standar deviasi & 0.58 & \\
& & & &
\end{tabular}

Hasil Tes Kemampuan Fisik Petinju Nasional Kalimantan Selatan ( X1 ) Skor tertinggi adalah 3.8 dan nilai terendah 2.9, nilai rata-rata adalah 3.4 dengan standar deviasi 0.25. Selanjutnya data hasil Tes Kemampuan Fisik Petinju Daerah Kalimantan Selatan ( X2 ) diperoleh nilai tertinggi adalah 4.2 dan nilai terendah 2.2, nilai rata-rata 3.1 dengan standar deviasi 0.58. Hasil lengkap dari item Tes Kemampuan Fisik Petinju Nasional dan Petinju Daerah Kalimantan Selatan dapat dilihat didiskripsikan pada tabel 2 berikut ini :

Tabel 2. Klasifikasi tingkat kemampuan Fisik Petinju Nasional dan Petinju Daerah Kalimantan Selatan

\begin{tabular}{|l|c|l|c|}
\hline \multicolumn{2}{|c|}{ Petinju Nasional } & \multicolumn{2}{c|}{ Petinju Daerah } \\
\hline Klasifikasi & Jumlah & Baikasi & Jumlah \\
\hline Baik Sekali + & - & Baik Sekali & - \\
Baik Sekali & - & Baik + & - \\
Baik + & - & Baik & - \\
Baik & - & Baik - & 1 orang \\
Baik - & 1 orang & Sedang + & - \\
Sedang + & 6 orang & Sedang & - \\
Sedang & - & Sedang - & 4 Orang \\
Sedang - & 1 Orang & Kurang + & 2 Orang \\
Kurang + & - & Kurang & - \\
Kurang & - & Kurang - & 1 Orang \\
Kurang - & - & Kurang Sekali + & - \\
Kurang Sekali + & - & Kurang Sekali - & - \\
Kurang Sekali - & - & - \\
\hline
\end{tabular}

A. Pengujian Persyaratan Analisis

Pengujian persyaratan analisis yangdilakkukan meliputi uji runtun dengan uji acak uji, normalitas dan uji homogenitas.

1. Uji Runtun dengan uji Acak.

Langkah awal uji keacakan adalah data hasil tes dilapangan diurutkan dari yang tinggi ke rendah untuk mencari median (Me), kemudian data yang lebih tinggi dari Me diberi tanda (+) dan yang kurang dari Me diberi

Dipublikasikan Oleh :

UPT Publikasi dan Pengelolaan Jurnal

Universitas Islam Kalimantan Muhammad Arsyad Al-Banjari Banjarmasin 
tanda (-), data yang digunakan dalam perhitungan adalah tingkat Kemampuan Fisik Petinju Nasional dan Petinju Daerah Kalimantan Selatan. Adapun urutan data dan median adalah sebagai berikut :

Kesimpulan: Hasil uji acak U hitung $=8$, sedangkan U tabel ( $4-14)$, Jadi U hitung terleta di antara U tabel dengan demikian sampel diambil dari populasinya secara acak.

2. Uji Normalitas dengan uji Lilliefors.

Tabel 3. Hasil Uji Normalitas tingkat Kemampuan Fisik Petinju Nasional Kalimantan Selatan (X1) dan tingkat Kemampuan Fisik Petinju Daerah Kalimantan Selatan (X2).

\begin{tabular}{|c|c|c|c|c|}
\hline Variabel & \multicolumn{1}{|c|}{ Hipotesis } & $\mathrm{L}_{\mathrm{o}}$ & $\mathrm{L}_{\mathrm{t}(\alpha=0,05 \mathrm{n}=8)}$ & Kesimpulan \\
\hline $\mathrm{X}_{1}$ & $\begin{array}{l}\mathrm{H}_{\mathrm{O}}: \text { Populasi berdistribusi normal } \\
\mathrm{H}_{\mathrm{i}}: \text { Populsi tidak berdistribusi } \\
\text { normal }\end{array}$ & 0,2500 & 0,285 & $\begin{array}{c}\text { Terima } \mathrm{H}_{\mathrm{o}} \\
\text { (Normal) }\end{array}$ \\
\hline $\mathrm{X}_{2}$ & $\begin{array}{l}\mathrm{H}_{\mathrm{o}}: \text { Populasi berdistribusi normal } \\
\mathrm{H}_{\mathrm{i}}: \text { Populsi tidak berdistribusi } \\
\text { normal }\end{array}$ & 0,2500 & 0,285 & $\begin{array}{c}\text { Terima } \mathrm{H}_{\mathrm{o}} \\
(\text { Normal })\end{array}$ \\
\hline
\end{tabular}

Keterangan:

$\begin{array}{ll}\mathrm{X} 1 & =\text { Variabel tingkat Kemampuan Fisik Petinju Nasional } \\ \mathrm{X} 2 & =\text { Variabel tingkat Kemampuan Fisik Petinju Daerah } \\ \mathrm{Ho} & =\text { Hipotesis nol } \\ \mathrm{Hi} & =\text { Hipotesis alternatif } \\ \text { Lo } & =\text { Harga L hasil pengamatan atau perhitungan } \\ \mathrm{Lt} & =\text { Harga multak L tabel }\end{array}$

3. Uji Homogenitas

Tabel 4. Hasil Uji Homogenitas Gabungan Varians Populasi.

\begin{tabular}{|c|c|c|c|}
\hline \multicolumn{1}{|c|}{ Hipotesis } & $\chi^{2}$ & $\chi_{\mathrm{t}(\alpha=0,05)(\mathrm{dk}=1)}^{2}$ & Kesimpulan \\
\hline $\mathrm{H}_{\mathrm{o}}: \sigma_{1}{ }^{2}=\sigma_{2}{ }^{2}$ & 4.46 & 5,99 & ${\text { Terima } \mathrm{H}_{\mathrm{o}}}_{(\text {Homogen })}$ \\
$\mathrm{H}_{\mathrm{i}}: \sigma_{1}{ }^{2} \neq \sigma_{2}{ }^{2}$ & & & \\
& & & \\
\hline
\end{tabular}

B.Pengujian Hipotesis

Tabel 5. Hasil uji hipotesis perbandingan tingkat Kemampuan Fisik Petinju Nasional (X1) dengan tingkat Kemampuan Fisik Petinju Daerah (X2).

\begin{tabular}{l|l|l|l} 
Hipotesis & $\mathrm{t}_{\mathrm{o}}$ & $\mathrm{t}_{\mathrm{t}}(0,05)(\mathrm{dk}=14)$ & Kesimpulan \\
\hline
\end{tabular}

Dipublikasikan Oleh :

UPT Publikasi dan Pengelolaan Jurnal

Universitas Islam Kalimantan Muhammad Arsyad Al-Banjari Banjarmasin 


\begin{tabular}{|c|c|c|c|}
\hline $\mathrm{H}_{\mathrm{o}}: \mu \mathrm{X}_{1}: \mu \mathrm{X}_{2}=0$ & 1,34 & 1,76 & $\begin{array}{c}\text { Terima } \mathrm{H}_{\mathrm{o}} \\
\mathrm{H}_{\mathrm{i}}: \mu \mathrm{X}_{1}: \mu \mathrm{X}_{2} \neq 0\end{array}$ \\
\end{tabular}

Berdasarkan hasil perhitungan uji hipotesis diketahui $\mathrm{t}(0,95)$ dengan $\mathrm{dk}=14$ dari daftar distribusi sudut adalah 1,76 sehingga diterima Ho karena to $=1,34$ terletak antara - 1,76 dan 1,76". Dengan demikian dapat disimpulkan tidak ada perbedaan antara tingkat Kemampuan Fisik Petinju Nasional (X1) dengan tingkat Kemampuan Fisik Petinju Daerah (X2).

\section{REFERENSI}

Anton Hermawan. 2012.Perbandingan ketepatan shoting kegawang menggunakan kaki bagian dalam dan kaki bagian luar pada tim sepak bola Banjarbaru. : Jurusan Pendidikan Olahraga dan Kesehatan FKIP UNLAM.

Djoko Lelono. 1999. Pedoman Penulisan Skripsi. Banjarbaru : Jurusan Pendidikan Olahraga dan Kesehatan FKIP UNLAM.

Djoko Lelono. 2004. Evaluasi Pengajaran Pendidikan Jasmani. Banjarbaru : Jurusan Pendidikan Olahraga dan Kesehatan FKIP UNLAM.

Harsuki. 2003. Perkembangan Olahraga Terkini. Kajian Para Pakar. Jakarta : Raja Grafindo Persada

Edy D.P Duhe. 2012. Pengaruh pelatihan shadow boxing dengan metode interval Terhadap peningkatan Kapasitas aerobik maksimal (Studi Pada Petinju Sasana FIKK Universitas Negeri Gorontalo)

Leo syahputra. 2008. Kamus besar bahasa indonesia: Lima bintang

KONI pusat. 1999. Pelaksanaan dan hasil program pelatihan Olahraga. Jakarta : KONI pusat

Moeslim, Mochamad. 1968. Test Pengukuran Dalam Olahraga : Yogyakarta : Sekolah tinggi olahraga Yogyakarta.

Nurhasan .1998. Penilaian pembelajaran Penjaskes. Jakarta : Universitas Terbuka

PENYUSUNAN NORMA KEMAMPUAN FISIK ATLET PENCAK SILAT SE-DIY (http://eprints.uny.ac.id/9069/1/1\%20-\%2008602241061.pdf)

Sastropanoelar, S, 1992. Pendidikan Kesegaran Jasmani. Jakarta: Depdikbud.

Sifat dasar dan pengertian perbandingan http://padmimonang.wordpress. Com /2012/10/20/sifat-dasar-danpengertian-perbandingan-hukum/

Sudarno SP. 1992. Pendidikan Kesegaran Jasmani. Jakarta : Depdikbud.

Sudjana. 2005. Metode Statistika. Bandung: Tarsito.

Universitas pendidikan indonesia (http://repository.upi.edu/operator/ uplhttp://file.upi .edu/Direktori/FPOK/JUR._PEND._OLAHRAGA/1965)

Dipublikasikan Oleh :

UPT Publikasi dan Pengelolaan Jurnal

Universitas Islam Kalimantan Muhammad Arsyad Al-Banjari Banjarmasin 